\title{
Otoño, invierno y primavera: tres trimestres para una experiencia de inclusión con arteterapia grupal en una escuela rural
}

\author{
Fania MOLINA $^{1}$ \\ faniamolina@yahoo.es
}

Enviado: $19 / 05 / 2011$

Aceptado: 12/10/2011

\section{RESUMEN}

Recorrido por una experiencia arteterapéutica grupal, dentro de un contexto educativo y rural, en el que la creación artística libre se convierte en catalizador de dinámicas interpersonales. La experiencia se realiza con un grupo pequeño de niños y niñas, de edades comprendidas entre 7 y 12 años, que conviven tanto dentro como fuera del aula. Este contexto confiere al grupo un carácter especial, añadiendo complejidad a sus relaciones, tanto a nivel latente como manifiesto. A través del arteterapia se pretende que aprendan a elaborar y comprender las diferencias interpersonales a través de un recorrido de autodescubrimiento donde se pongan en juego dimensiones individuales y grupales.

Palabras clave: Arteterapia grupal, ámbito escolar y rural, dinámica y evolución grupal, vinculación, robots

\section{Referencia normalizada}

MOLINA F. (2011). "Otoña, invierno y primavera: tres trimestres para una experiencia de inclusión con arteterapia grupal en una escuela rural”. En Arteterapia: Papeles de arteterapia y educación artística para la inclusión social Vol.: 6. Páginas 51-69. Madrid. Servicios de publicaciones UCM.

\section{SUMARIO}

Introducción. Taller de arteterapia: características del grupo. Objetivos. Encuadre Elección de un formato grupal. Otoño: primer trimestre. Invierno: segundo trimestre. Primavera: tercer y último trimestre.A modo de conclusión. Referencias bibliográficas.

\section{Autumn, Winter, and Spring; three seasons for an experience of incorporation with grupal Art therapy in a rural school}

\begin{abstract}
Overview of a experience with a created art therapy group in order to comprehend most group dynamics in an specific country land educational context. The experience is made with a small group of children with ages among 7 and 12, who belong to the same small village and cohabite either inside the same classroom or outside. This fact creates a complex relationship in either latent or manifest behaviour. Through art therapy it is pretended that these children were able to learn how to accept
\end{abstract}

\footnotetext{
${ }^{1}$ Arteterapeuta por la Universidad de Barcelona.
} 
their differences and others' differences, and at the same time to enable them to make new discoveries towards self -knowledge, individually and in groups.

Keywords: Grupal arttherapy, rural academic environment, group dynamics and group evolution bonding, robots.

\section{CONTENTS}

Introduction.- Art therapy workshop: group caracteristics.-Goals and setting.- Choosing a group format.- Autunm: first trimestre.- Winter: second trimestre.- Spring: third and last trimestre.- A way of conclusion.

\section{INTRODUCCIÓN}

Ya Froëbel, basándose en la pedagogía de Pestalozzi y en la ideología de Kant habla de cómo el juego a través de las actividades artísticas, supone una forma de expresión personal y de autoconocimiento. "Froëbel entendió el dibujo y la actividad artística como una descripción del interior del individuo, de modo que lo que debia hacer el niño era representar su interioridad mediante colores y formas" (Barragán, 1997: 193). Posteriormente la expansión del psicoanálisis propició que algunos artistas y educadores como Florence Cane, Margaret Naumburg o Edith Kramer se psicoanalizaran y combinaran esta experiencia con sus habilidades pedagógicas y artísticas, proporcionando el primer escenario para el arteterapia en las aulas.

Con el florecimiento de la psicología de grupos desde los años 40 hasta los 60 tanto en América como en Gran Bretaña se fue enriqueciendo el panorama de la metodología del arteterapia con formato grupal.

Partiendo de estas primeras fuentes en el inicio del Arteterapia grupal como método complementario en la educación, parece interesante efectuar un recorrido desde lo individual a lo grupal y ahondar en el trabajo grupal con arteterapia.

\section{TALLER DE ARTETERAPIA: CARACTERÍSTICAS DEL GRUPO}

Inicialmente los talleres estaban dirigidos a un grupo de 5 niños y 3 niñas de edades comprendidas entre 7 y 12 años que convivían dentro de una misma aula en una Escuela Rural sita en Segovia, si bien este número inicial fue variando debido a nuevas incorporaciones.

Una de las características que presentaba el grupo era la vinculación familiar:

- L (el menor de los niños), de 7 años de edad y P, una niña de 10 años, eran hermanos.

- $\mathrm{G}$, una niña de 12 años, $\mathrm{H}$, un niño de 10 y I, de 8 años, conformaban un grupo familiar extranjero procedente de Bulgaria (que llevaban en la escuela 3 años):

- Dos hermanos: M, de 10 años en el momento de empezar el taller y $\mathrm{N}$ de 8 .

- J, de 11 años de edad, era el único que no poseía lazos familiares dentro del grupo. 
Todos ellos conformaban prácticamente la única población infantil estable en el pueblo durante los periodos no vacacionales, por lo que convivían tanto dentro como fuera del aula. Como consecuencia a la vecindad y convivencia, en el aula de Arteterapia muchas de las dinámicas que acontecieron en el grupo, formaban parte de otras previas, establecidas y fijadas con anterioridad.

La creación de este grupo de Arteterapia se consideró, precisamente, como medio para equilibrar parte de las fuerzas generadas por estas dinámicas, que convergían en la escuela y no escapaban a la observación de su tutora; el taller, si bien estuvo enmarcado dentro de lo educativo, se configuró sobre todo como un espacio para favorecer la creatividad en el sentido terapéutico de la palabra, como posible pilar para el cambio (López F. Cao ,2006).

\section{OBJETIVOS}

Los enfoques socioculturales del tratamiento arteterapéutico, coincidiendo con los tratamientos exclusivamente grupales, consideran al individuo como parte de un sistema global de relaciones que irremisiblemente está influido por condicionantes socioculturales. Por ello, en la mayoría de los casos, dicho tratamiento contribuirá a desarrollar la identidad social haciendo énfasis en las relaciones interpersonales.

En el grupo con el que se llevó a cabo esta experiencia dichas relaciones estaban, en cierto sentido, muy definidas desde fuera: tanto desde el aula, donde aprendían todos juntos, hasta en sus vidas cotidianas, donde no les quedaba más remedio que jugar entre ellos la mayoría del tiempo. Sin duda, analizar estos vínculos generados en la interacción con los demás es fundamental para entender la globalidad del individuo.

A través del Arteterapia se buscaba proporcionar un espacio que permitiera hacer visibles los comportamientos emergentes en las relaciones cotidianas y ser más conscientes de ellos, y que por lo tanto sirviera para empezar a reconocer las diferencias.

Atendiendo a estas primeras consideraciones se presentó un proyecto a los padres/madres y tutores del centro basado en los principios de Liebmann (1986), a través del cual fuera posible:

a) La utilización de técnicas artísticas para el auto-conocimiento, el desarrollo personal, la mejora de la salud y la calidad de vida. Se persigue la apertura a la creación sin prejuicio: la escucha interior, la atención y la espontaneidad

b) Desarrollo de las habilidades cognitivas y lingüísticas a través del lenguaje artístico.

c) Desarrollo del juego artístico para equilibrar las fuerzas existentes en el grupo-clase, ayudando a establecer relaciones satisfactorias y enseñando al niño a compartir en lugar de competir.

Durante este proceso también se buscaron algunos beneficios colaterales como:

- Ofrecer una alternativa más para la comunicación.

- Expresar sentimientos que serían difíciles de expresar de otra manera.

- Incrementar la autoestima y la confianza. 
- Desarrollar herramientas positivas ante el enfrentamiento.

- Aprender a entenderse y a entender, a conocerse y conocer.

\section{ENCUADRE}

Encuadre geográfico.- Para crear un espacio adecuado se consiguió un aula distinta a la habitual, con el fin de colocar la experiencia en otro plano de intersubjetividad.

Encuadre temporal.- Las sesiones se llevaban a cabo cada miércoles, durante una hora y media, y estructuradas en tres periodos bien diferenciados (Liebmann, 1986):

- Bienvenida y toma de contacto: 15 a 20 minutos.

- Proceso creativo: 45 minutos aproximadamente.

- Intercambio de experiencias y reflexión fundamentada en la escucha y el respeto al otro. Se dio como consigna, que se intentara no juzgar. Los chicos y chicas debían hablar por turnos de sus trabajos y sus dificultades para ejecutarlos, y/o sensaciones ante el resultado de uno mismo y de los otros.

\section{Encuadre interno.-}

a) Permitir fluir libremente la intuición y la espontaneidad con los materiales visiblemente colocados, proporcionando una gran variedad de materiales artísticos (pinturas de todo tipo, arcilla, carbón, material reciclado, etc...)

b) Permitir trabajar sin interesarse por el resultado final, atendiendo al proceso.

c) Considerar la creación como proceso de transformación.

\section{ELEGIR UN FORMATO GRUPAL}

Dadas las características especiales ya mencionadas dentro del grupo a tratar, parece interesante señalar que durante la experiencia se atendieron a varios modelos grupales (Case y Dalley, 1992). El grupo fue pasando de uno a otro casi en una sucesión lógica e histórica, que se resumiría así:

-The Studio-based: históricamente se utilizó en los principios del arteterapia grupal. Era un modelo abierto, donde los componentes entraban y salían. El énfasis se encontraba en los procesos creativos individuales más que en las dinámicas grupales, favoreciendo el diálogo en torno a las obras de cada individuo. En el contexto de esta experiencia -la escuela rural- podría hablarse también de grupo abierto; se producen aquí cambios constantes del alumnado, especialmente inmigrante, que aparece y desaparece en diferentes épocas del año según las necesidades económicas familiares. Esto obligaba a tener un encuadre más abierto, adaptado al funcionamiento del centro, que permita la incorporación de nuevos miembros.

Por otro lado, así como históricamente este fue el primer modelo de Arteterapia grupal, también en esta experiencia fue el primero de los formatos en aparecer. 
-Theme-Centred Group. La influencia del psicoanálisis a partir de los años 60 puso el acento en conceptos estructurales (encuadre) relacionados con el tiempo, el lugar y la frecuencia de los encuentros. Se trataba de un modelo grupal (Waller, 1991; Liebmann, 1986) centrado en la producción de ejercicios artísticos, a partir de consignas y temas que podían ser sugeridos por los arteterapeutas o consensuados por los participantes. Desde este enfoque el trabajo artístico estructurado seguía funcionando como medio para comprender los problemas individuales de cada miembro.

Este enfoque apareció durante el segundo trimestre de nuestra experiencia, pero hubo que valorar también los peligros de los que advierte Molloy (mencionado por Franks y Whitaker, 1988) sobre la cualidad potencialmente invasiva de las consignas. Como señala McNelly (1983), con la utilización de consignas plásticas se corre el riesgo de descubrir material inconsciente con demasiada rapidez lo que puede provocar sentimientos persecutorios entre los miembros.

-Group Analytic or Interactive Art Therapy. Esta orientación se basaba en la teoría de grupos analíticos de Foulks, Bion y Yalom entre otros, donde la producción de imágenes se entendía como una parte de la dinámica grupal, y donde la interacción se producía entre todos los miembros incluidos los arteterapeutas. Estaba basado en la técnica del "grupo centrado en el grupo", en el análisis de la propia dinámica.

La técnica está inspirada en las ideas de Kurt Lewin, en la que se considera al grupo como una totalidad.

Foulks habla del concepto de "matrix" (matriz), que es una metáfora para expresar una especie de "network" (red) donde se producen los procesos mentales individuales, actuando como un contenedor y un entorno capacitador de cada individuo dentro de un grupo. La coherencia del grupo es fundamental para que este funcione terapéuticamente. Este proceso de coherencia funciona tanto consciente como inconscientemente dentro del grupo. Desde esta base teórica es el grupo mismo el que gestiona los temas, las técnicas artísticas a utilizar y el tiempo que se va a dedicar a cada fase.

En nuestro caso, dada la edad de los componentes del grupo y el contexto educativo, se trabajaba desde un lugar algo más directivo, estructurando la hora y media de la sesión en tres etapas bien diferenciadas como se han mencionado y siguiendo a algunos autores como Greenwood y Layton, (1987) que creían que el interés principal debía recaer en los temas discutidos por el grupo y que el terapeuta debía devolverlos de forma moderada con ayuda de las imágenes.

Tras lo aquí expuesto, se podría decir que la estructura grupal de la experiencia que se presenta, desarrollada durante los tres trimestres de un curso escolar, fue variando en función de un proceso de ajuste y reajuste, respondiendo así a las separaciones y los cambios de cada trimestre. Progresivamente se fue aprendiendo a utilizar el medio y el taller de Arteterapia de un modo personal, pasando de un formato grupal a otro, siguiendo el ritmo marcado por las estaciones que separaban de manera natural cada uno de estos trimestres. 


\section{OTOÑO: PRIMER TRIMESTRE}

El otoño nos prestó su marco de ocres para comenzar una andadura que se caracterizó principalmente por poner de manifiesto reacciones tan lógicas como esperables: el miedo a lo desconocido, una insistente búsqueda de límites y la aparición de roles.

\section{Miedo a lo desconocido}

Al comienzo, durante las primeras sesiones, era notable la necesidad de definir qué era un grupo de Arteterapia, para qué servía, qué se esperaba de cada uno, cómo se habían de utilizar los materiales, etc., Hubo que trabajar las ansiedades y los miedos que surgían ante un trabajo artístico no dirigido distinto al que estaban habituados .Preguntas como: "¿vamos a tener nota?, ¿De verdad puedo hacer lo que yo quiera?, ¿Pero qué hago?”, se sucedían. En cierto modo parecía normal que al principio se viviera este espacio como una amenaza desestructurada, y se conectara con cierto grado de ansiedades catastróficas, que hubo que contener y apaciguar: explicando en que consistían las sesiones y respondiendo a sus preguntas y dudas.

Esta dificultad ante un medio nuevo de experimentación y libertad se punía de manifiesto sobre todo a la hora de elegir los materiales que se querían utilizar en las sesiones. En consecuencia, durante las dos primeras sesiones el resultado terminaba con la tendencia generalizada de utilizar los mismos materiales al unísono, casi siempre siguiendo al primero que elegía un material, que normalmente era un miembro masculino de mayor edad.

Los primeros trabajos eran referencias a su entorno habitual, como la casa, el paisaje, los primeros colores otoñales. A través de los materiales surgían temas muy recurrentes como: "quien es malo, quien es bueno", "compartir", "malgastar ", etc. Temas que por otro lado, provocaban en mi una contratransferencia muy cercana al rol de profesor, que es lo que los "alumnos y alumnas" esperaban, siendo en ocasiones muy difícil eludir.

Otras veces, durante estas primeras sesiones, se seguían las consignas que uno de los miembros proponía, cuando aparecían nuevos materiales útiles para la sesión, como ocurrió cuando aparecieron las carpetas que iban a contener sus trabajos. En cierto modo, como se mencionaba mas arriba, e indirectamente, se podría decir que se favoreció la formación de un grupo centrado en un tema. Aquí el grupo siguió de nuevo una propuesta de unos de los chicos mayores de modificar las carpetas de forma individual y personalizada, con el fin de "no confundir unas con otras", literalmente.

A partir de esta propuesta, poco a poco se fueron evidenciando algunos de los subgrupos operativos dentro de la unidad grupal, que irían conformando durante el transcurso de la experiencia un baile de alianzas muy significativo.

Desde los primeros momentos aparecieron situaciones y dinámicas muy llamativas; a veces la escasez de material obligaba a compartir rodillos, papeles de colores, colas, etc., provocando alianzas, dando lugar a significativos episodios de splitt grupal, que también fueron visibles a lo largo de las producciones plásticas. 
Los roles protectores de los hermanos mayores hacia los pequeños no tardaron en aparecer, tanto o más como los roles competitivos y de liderazgo. Los primeras dificultades que conformaban los problemas vinculares entre ellos llegaron con los primeros fríos otoñales. Entre los primeros objetivos surgió el de convertir el taller en un espacio de reflexión y de recuperación de redes solidarias. Lo vincular era origen del conflicto pero también medio para su resolución.

Durante estas primeras sesiones, la posición como arteterapeuta fue complicada. Primero limitada a actuar para trascender lo manifiesto, intentando crear las condiciones para explorar, experimentar, desplegar y elaborar, más que calmar o apaciguar. Pero en seguida pasaría a convertirme en la depositaria de un montón de desechos mal digeridos, que necesitaban ser vomitados e inundaban el espacio, provocando a veces un sentimiento contratransferencial muy cargado de ansiedad catastrofista.

\section{Búsqueda de límites}

Parecía difícil durante los primeros encuentros mantener la atención en los acontecimientos que estaban pasando durante el aquí y el ahora de la sesión. Se hacían referencias constantes a peleas que habían tenido anteriormente, o a las diferencias entre los mayores y los pequeños de la clase, así como a las dificultades entre hermanos dentro del propio núcleo familiar. Esta fue una de las características constantes, y tuvo una gran relevancia dentro del inconsciente grupal, cuando se analizaba el funcionamiento de la transferencia grupal como un todo, pues en muchas ocasiones, buscaban un juez que pudiera marcar la diferencia entre lo justo y lo injusto.

En muchas ocasiones las intervenciones eran percibidas como escasas y poco útiles, ya que el juego de lucha de poder se venía abajo cuando se acogían sus quejas sin entrar en valoraciones juiciosas, focalizando la atención hacia sus trabajos artísticos como respuesta y asentando los límites de la sesión hacia lo puramente creativo.

La hipótesis por aquel entonces era que se estaba empezando a probar el espacio como un entorno diferente para poder expresar sentimientos y sensaciones que en el resto de los contextos externos no se permitían, por ser inadecuados o encontrar poca resonancia. En este sentido se estaban probando los límites de lo que se podía o no decir en este grupo. Y esto me pareció interesante que se viera favorecido, porque desde este punto de vista este grupo era un grupo diferente, lúdico, experimental, que pocas veces se daba en contextos educativos.

En otras ocasiones, casi como una extensión de lo anterior, el taller servía al grupo constantemente para probar los límites del encuadre, sobre todo para ver hasta donde podían llegar con el manejo de los materiales, con problemas para sentarse en uno u otro sitio, o con discusiones para ponerse de acuerdo para seguir un orden en la presentación de los trabajos artísticos, así como la atención que se prestaban unos a otros durante estas. La contratrasferencia era confusa a veces y llevaba a pensar si era mejor adoptar el rol de maestro poniendo ciertos límites naturales, por otro lado muy demandados, o utilizar lo que allí surgía para que el 
grupo se auto regulara, dirigiendo la atención hacia los trabajos y procesos mas expresivos, aunque necesariamente hubo que dirigir al principio sobre todo, estas actuaciones. Pongamos un ejemplo:

Durante las últimas sesiones de Diciembre se generalizó entre el subgrupo masculino.la fabricación de objetos de "guerra" como: tirachinas, pistolas y artilugios para lanzar munición de plastilina, que empezaron a utilizar durante el taller y que rápidamente hubo que limitar, para no convertir el aula en una batalla campal.

Parecía curioso observar como fueron apareciendo poco a poco dos subgrupos bien diferenciados. Las niñas, sin embargo, se instalaron en un rol de naturaleza tranquila, pasiva, como espectadoras de lo que allí ocurría, pero que no tardaron en mostrar su preocupación porque algo pudiera ser dañado con la munición de plastilina.

Hasta entonces, ellas habían estado investigando y utilizando diferentes materiales, mas allá de las temperas, acuarelas, pinturas, etc., que al principio se venían utilizando. Sin embargo, durante estas manifestaciones guerreras masculinas utilizaron uno de los mismos materiales empleados en la construcción de los tirachinas, los globos, para ser utilizados de manera significativamente distinta.

Otra de las dificultades lógicas durante estos primeros encuentros de otoño, fue aprender a compartir las experiencias de cada uno de sus procesos creativos y pasar de adjetivos tópicos de expresión refiriéndose las obras ya terminadas de los demás. De "bonito" y "feo" a dar impresiones e incluso sugerencias

Comunicar y escuchar era en ocasiones una tarea titánica que disparaba las resistencias individuales dentro del grupo así como las primeras dinámicas grupales de diferenciación y búsqueda de singularidad dentro del contexto grupal.

Durante este primer periodo parecía existir una fuerte transferencia grupal que colocaba a la figura de la arteterapeuta como líder y moderadora; el rol de profesor estaba muy presente y las intervenciones eran muy activas. Poco a poco, y a tenor de las supervisiones, fue posible modificar esta posición, hasta convertirla en la de alguien que acompañaba, animaba y facilitaba la creación y experimentación, promoviendo un espacio de juego.

\section{Aparición de los roles}

Era notorio como iban apareciendo durante estas primeras sesiones de siembra otoñal las necesidades de identidad de cada miembro, utilizando, eso si, poco a poco materiales más personales, como si las carpetas hubieran funcionado como catalizadores para empezar a marcar esas diferencias bien definidas entre unos y otros.

Fueron muchos los trabajos que se fueron desarrollando alrededor del nombre propio de cada uno utilizando diferentes materiales: plastilina, rotuladores, con plásticos, con cuerdas, tapas, etc.

Desde ese momento comenzaron a ponerse de manifiesto las diferentes individualidades: 
- "J" (varón, 11 años), empezó a aparecer como el elemento disruptivo, que se enfadaba constantemente por diversas razones con los compañeros del grupo. En ocasiones muy peleado con el resto, no parecía estar muy valorado por nadie entre ellos. Sus trabajos eran bastante imitativos, y casi siempre necesitaba de alguien para empezar a crear algo, que le dieran la primera pauta. Para él parecían ser muy importantes las alianzas y defender su posición en el grupo, aunque lo hacía a base de discusiones constantes y agresiones de tipo verbal, e incluso físico.

-"M" (varón 11 años), de una forma más pasiva creaba mucha controversia en el grupo, pero por otro lado parecía sentirse muy seguro de si mismo y mantener un estatus de liderazgo con respecto al grupo. Manifestaba una gran inventiva y capacidad creadora, necesitando en algunas ocasiones varios trabajos para saciar su capacidad expresiva no verbal.

-"N" (hermano de M, 8 años), intentaba interactuar de alguna manera con los mayores siempre que encontraba una brecha por donde entrar, pero casi siempre era parado en seco y relegado a un sitio entre los pequeños, desde donde cooperaba con otro de los hermanos menores en diversos trabajos, formando un subgrupo de "los pequeños"

-"P", ( niña de 10 años), aparecía como muy concreta en sus trabajos, y tendía a representar la voz crítica del grupo, poniendo de relevancia en múltiples ocasiones la falta de cooperación entre unos y otros, recordando los límites a los demás .En sus trabajos se denotaban también mucha organización y consonancia.

- "L" (hermano de P de 7 años), era muy imaginativo y trataba de encontrar el medio en el que se encontraba cómodo. En cierto modo se notaba que era el menor de la clase y que estaba relegado a la cooperación si alguno de los mayores se lo permitía. Conformaba junto a $\mathrm{N}$ el subgrupo de los pequeños.

-"I" (niña emigrante de 8 años), destacaba como uno de los miembros grupales mas independientes, aunque desde las primeras sesiones mostrara grandes dificultades para conseguir lo que se proponía y su frustración se ponía de manifiesto casi constantemente. Parecía haber un aspecto depresivo que la hacía no valorarse, y en muchas ocasiones descartaba sus obras y se quejaba de que todo la salía mal, aspecto por el cual se trabajó mucho durante el primer trimestre individualmente con ella.

-"G", (12 años al comienzo del taller) era la mayor del grupo, y como tal actuaba en muchas ocasiones, aunque solía tener problemas para expresar lo que a ella misma le ocurría; salía en defensa de cualquiera de los miembros cuando ella lo considera oportuno, haciendo uso de un fuerte rol maternal-protector.

-"H" (varón, de 10 años), hermano de las dos niñas anteriores, poseía una posición intermedia que promovía alianzas con los mayores o con los pequeños indistintamente. Muchas veces, pese a su cara sonriente, trabajaba con rabia en los materiales, siendo este un medio muy apropiado para descargar sus emociones. 


\section{INVIERNO: SEGUNDO TRIMESTRE}

La latencia invernal casi se confundía con el emergente grupal. A partir de este trimestre,y tras un conocimiento un poco mas representativo de los roles individuales, se fueron generando dinámicas grupales mas exageradas, que llevaron a constituir un giro en las intervenciones hacia lo grupal y sus transferencias (Bion, 1946 ,1952, 1961; Ezriel 1950, 1973). Las hipótesis e intervenciones sobre lo que emergía, se dirigían a tratar al "grupo en su conjunto", casi como si fuese un solo individuo, pasando de un enfoque intrapersonal a otro multipersonal, pues en el grupo iban apareciendo mas claramente problemas estructurales disfuncionales.

Por todo ello, en este punto, parece interesante mencionar los tres supuestos básicos de los que nos habla Bión en relación al trabajo grupal:

-La dependencia: idealización del líder.

-El ataque y fuga: bajo el dominio del líder, el grupo o parte de éste, reacciona frente a un enemigo común. Va asociado la aparición del "chivo expiatorio".

-El emparejamiento: los miembros del grupo mantienen una expectativa esperanzada ante una pareja, porque espera que de ellos surja algo que les libere del chivo expiatorio.

\section{La dependencia}

Hacia el segundo trimestre los subgrupos parecían ir tomando una forma, digamos estereotipada, atendiendo a semejanzas e intereses comunes según edades y genero.

Tras el descanso/ separación de Navidad, los chicos y chicas parecían entrar más cómodos al aula y curiosamente se sentían mas seguros de sacar temas singulares que les afectaban en el aquí y ahora de cada sesión, atendiendo a los acontecimientos que se iban sucediendo durante el proceso creativo de cada uno.

Fueron apareciendo colaboraciones entre los miembros de los distintos subgrupos, que se iban poniendo de manifiesto en los trabajos compartidos y que a veces eran criticados por los demás. Siguiendo los principios de Bion (1979) en relación a los conflictos entre grupos, se observaba como las defensas primitivas de escisión y proyección aparecían de un modo que se creaban situaciones de todo o nada, en las que el grupo parecía sentir una cohesión dogmática interna al tiempo que percibía al otro (subgrupo/individuo) como algo totalmente ajeno y amenazante.

A partir de Febrero apareció un nuevo varón en escena, "K". (misma edad que "L", 7 años), llegó a la escuela transitoriamente, porque su madre estaba enferma y se habían venido al pueblo para que ella reposara una temporada.

$\mathrm{J}$ parecía haber adoptado un rol paternalista, enseñando a $\mathrm{K}$,(que aparecía ausente y desubicado), los materiales, y fabricando un tirachinas, como en un gesto que parecía, simbólicamente hablando, una forma de inclusión en el clan masculino, que hasta este momento había seguido en la "carrera armamentística", sobretodo de mano de él mismo y de $\mathrm{M}$, cuyo último trabajo en alianza con J, había sido la construcción de un cañón con diversos materiales reciclados. 
Debido a esta interferencia, M pareció sentirse algo desplazado, y comenzó a trabajar de forma más profusa en múltiples cosas incansablemente. Mientras tanto el equipo de menor edad formado en las sesiones anteriores, siguió jugando ajeno a los nuevos acontecimientos y las chicas siguieron experimentando con materiales nuevos.

A partir de este momento aparecería un trabajo grupal muy interesante alrededor de un robot, con la participación de todos los varones, (que era abastecido con material de reciclaje por el grupo femenino), excepto por la nueva pareja formada por $\mathrm{J}$ y $\mathrm{K}$, que por otro lado, intentaban emular algunos de los objetos que se estaban fabricando en el grupo masculino.

Los objetos que $\mathrm{J}$ y $\mathrm{K}$ fabricaban durante esta sesión estaban hechos de los mismos materiales que el robot. Mientras tanto las chicas, atentas a los nuevos acontecimientos, parecían tener la necesidad de diferenciarse a través de otro trabajo grupal femenino.

Desde la posición de arteterapeuta comenzaba a registrarse una fuerte sensación contratransferencial de intranquilidad y desasosiego. Ante lo que parecía angustia por sentirse apartado en el grupo, las manifestaciones agresivas de $\mathrm{J}$ empezaron a sucederse: se reía cada vez que a sus compañeros se les rompía el robot, les prohibía que cogieran los materiales que él acumulaba en su mesa de trabajo, o hacía alusiones despectivas a los trabajos comunes de las chicas. Al unísono, parecía que el grupo había empezado a actuar su esperanza de librarse de él a través de su alianza con $\mathrm{K}$, trabajando alegremente alrededor del robot.

Al final de la sesión, I, llevada por la rabia, realizó un dibujo con palabras y alusiones despectivas hacia $\mathrm{J}$, que pareció provocar en el grupo un sentimiento ambivalente de resonancia y rechazo. Ella destruyó rápidamente su trabajo y lo tiró a la papelera. El grupo parecía rechazar aquellas proyecciones más negativas que, a modo de talismán (Schaverien, 1987), se habían depositado en el trabajo de I. El tono agresivo parecía seguir inundándolo todo y $\mathrm{J}$ amenazaba literalmente al grupo con no volver más, como si fuera a él mismo al que hubieran tirado a la papelera.

\section{Ataque y fuga: el chivo expiatorio}

Llegados a este punto, se había puesto en evidencia tanto el rechazo del grupo hacia $\mathrm{J}$, como el de $\mathrm{J}$ al grupo. El emergente grupal aquí parecía ser un fuerte deseo de que J desapareciera y con él, todos los aspectos negativos del grupo.

$\mathrm{J}$ actuaba de manera impertinente y sus exploraciones artísticas parecían limitarse al mero hacer por hacer, muchas veces como excusa para poder acaparar el material del taller en su mesa y de esta manera, quizás demostrar su poder ante los demás.

Parecía faltar un "sostén" (holding), que J buscaba con ansiedad en sus interacciones, volcando en múltiples ocasiones esa necesidad en la arteterapeuta.

Cada vez se hacían más evidentes los problemas de $\mathrm{J}$ con el grupo, y el papel que él adquiría y promovía. Por otra parte, J parecía mantener un especial contencioso con quien fue primero su aliado: M. Este le rechazaba una y otra vez y 
se había convertido en el líder indiscutible de un nuevo proyecto masculino grupal: otro robot gigante

Kemberg, (citado por Bleichmar, en Avances en Psicoterapia Psicoanalítica, 1997) llama la atención sobre una dimensión manipulativa de la rabia narcisista, desde la que se intenta manipular el entorno para, de una forma imaginaria, empujarse a uno mismo hacia la imagen ideal. Durante estas sesiones parte de las intervenciones se dirigieron a recoger el malestar de J, manifiesto en la acumulación de materiales en su mesa, para que de esa forma pudiera ir tomando contacto con su actitud.

El resto del grupo parecía esconderse tras la recapitulación de los procesos de sus trabajos, como si intentaran mirar a otro lado para no ver como algunos de sus compañeros "bien considerados", estaban intentando aparentemente castigar a J por su dificultad en el vínculo.

\section{Intentos de vinculación}

El invierno iba llegando a su fin, y la dinámica seguía disparándose hacia la exclusión de J. Ahora K colaboraba con el resto del grupo, y J alternaba entre el mutismo y la rabia, explicitando repetidas veces su malestar en el grupo con expresiones como: "no me gusta estar aquí, porque siempre pasan cosas ".

Dice Pichón Rivière (1984) que cada rol se estructura en un interjuego de asunción y adjudicación de roles entre los miembros del grupo. La posición de J parecía reflejar, amplificado, un malestar grupal que evidenciaba tanto el miedo a la pérdida del rol como el miedo a un posterior ataque. En esta línea, las intervenciones se dirigieron también a señalar esta dinámica, exponiendo el carácter de "barullo" que parecía impregnar a procesos y obras y que a menudo daba lugar a explosiones de color y de rabia, pues se trabajaba muchos con las manos directamente sobre el papel, incluso llegando a destruirlas. Con las intervenciones se intentaba confrontar la actitud aparentemente razonada del grupo con las manifestaciones agresivas.

Solo una de las niñas fue capaz de crear un libro de firmas en un intento conciliador, que ponía de manifiesto su deseo de reunir de nuevo al grupo. Durante la revisión de las obras apareció este hecho y se expuso al grupo, en un intento de mostrar algo de esta ambivalencia: por un lado, hacer desaparecer los aspectos desagradables, y por otro, incorporarlo de alguna manera.

La importancia de J para el grupo se pondría de manifiesto en una de las sesiones, a la que no asistió. El grupo no paraba de hablar de él en tono crítico y despectivo, evidenciando paradójicamente su presencia. Esto sirvió para señalar y pensar acerca de lo útil que parecía ser para el grupo J. Parecía haberse convertido en una entidad que englobaba todo lo malo, lo desechable, lo que no gustaba; no sólo de él, sino también de todas las proyecciones del grupo.

Durante la sesión siguiente otra niña realizó un libro con páginas para cada uno, para reunirnos a todos. Mientras las dinámicas masculinas seguían radicadas en el terreno de la agresividad, las femeninas parecían explorar otros caminos. 
La última sesión del trimestre estuvo presidida por las despedidas, las vacaciones y el adiós de $\mathrm{K}$, una vez repuesta su madre, regresaba a su casa. Lo vincular parecía seguir presente y esta vez el grupo entero se lanzó a trabajar con plastilina unos móviles, propuestos por $\mathrm{M}$, que parecían hacer patente la necesidad de mantenerse comunicados. Estos trabajos sirvieron para hablar de la despedida en todas sus facetas, y de la necesidad que quizás tenía el grupo, de alguna manera, de seguir manteniendo el contacto.

Parecía que el grupo se había hecho eco de esta necesidad de vínculo, lo que hacía preguntarse acerca de si el proceso respondía a un dialogo destrucciónconstrucción de lo vincular. Lo deseable era que, en su aparente circularidad, fuera expandiéndose, fuera ampliándose su radio hasta configurar un movimiento en espiral (Pichón Riviére, 1988).

\section{PRIMAVERA: TERCER Y ÚLTIMO TRIMESTRE}

Después de las vacaciones de Semana Santa todo aparentemente volvía a ser como al principio. ¿O no? $\mathrm{K}$ ya no estaba. El emparejamiento milagroso pareció no funcionar. La realidad grupal del chivo expiatorio seguía muy presente, aunque sostenida por los procesos artísticos.

\section{La llegada de una niña nueva}

Al comienzo del trimestre, apareció una niña nueva "Ñ", de 9 años. $\tilde{N}$ era hija de emigrantes marroquíes. Era una niña muy delgadita y delicada, que hablaba muy bajito, y que instintivamente se colocó al lado de G que para entonces ya había cumplido 13 años. G se ocupó de ella desde la primera sesión atendiendo a su rol más maternal.

Con la aparición del nuevo elemento, comenzó un proceso de recolocación del grupo: las niñas se colocaron en fila hacia el lado interior de la sala y los muchachos adoptaron una posición complementaria, (separados por una gran mesa central), al grupo femenino. Era bastante significativo además, que dentro de todo este nuevo proceso de reubicación, apareciera de nuevo la necesidad de trabajar en cosas individuales.

Prácticamente todos los participantes volvieron a los trabajos con nombre propio, a excepción de dos de los chicos, que parecían estar bastante desubicados: J, que parecía seguir asumiendo su papel de rechazado grupal, y L que parecía mostrar bastante desconcierto con esta nueva tendencia individualista. Ambos buscaron durante la sesión situarse cerca o cooperativamente con otros, con poco éxito por ambas partes.

Mientras Ñ era dirigida e incluida en el club a través de G, que le había enseñado a hacer su propio teléfono móvil de plastilina, los dos muchachos terminaron identificándose con la niña nueva y cogieron dos pellas de plastilina y comenzaron a trabajarlas, pero de muy diferente manera. J golpeaba, estiraba y aplastaba la plastilina verde entre sus manos sin conseguir materializar apenas algún elemento; y terminó por realizar dos elementos diferenciados. L, por su parte, rehizo un celular, 
emulando a la niña nueva, que protegida y guiada había conseguido su "medio de comunicación".

Todo esto conducía a pensar en cuan diferente parecía estar presente el objeto contenedor para uno y para otro, y como éstos estaban constituidos tan diferentemente en uno y otro niño. Durante la presentación de los trabajos fue posible explicitar el curso de estas dos acciones, mencionando las similitudes y diferencias entre ambas. Gracias a eso el grupo pudo evidenciar como sus comportamientos servían de comparativa gestual y actoral.

Sin embargo, esto no pareció gustarle a J, que de nuevo parecía encarnar el chivo expiatorio y se defendía de la única manera que sabía hacer: con violencia, gritando. De nuevo comenzó a crearse una atmósfera incómoda y densa, con nuevos sentimientos ambivalentes muy lejos de la fantasía de un grupo ideal.

En este punto P puso la voz crítica, y fue capaz de confrontar como su hermano, aún sintiéndose igual que J, no actuaba como él. El grupo callaba, pero parecía mostrar su acuerdo con esta última observación.

\section{El nuevo robot}

Los niños de menor edad ( $\mathrm{L}, \mathrm{N}$ y $\mathrm{H}$ ) retomaron el gran robot en las sucesivas sesiones, haciendo caso omiso de los que parecían haber encontrado otros proyectos más interesantes.

M empezó poco a poco a sentirse atraído también por el gran robot, sobre todo cuando los pequeños encontraron una forma de armarle con los tirachinas de las primeras sesiones de otoño, incrustados en el pecho. Parecía atraerle este giro hacia lo beligerante del robot.

Quizá el robot estaba funcionando como contrapartida a J. Al igual que J manejaba y manipulaba constantemente la escena, el resto podía hacer lo que quisiera con ese robot del que no participaba él. Lo cogían y lo dejaban cuando querían. Le ponían los aditivos que más les gustaban, añadiendo o quitando a voluntad. Se había convertido en un elemento inquietante, sujeto a múltiples transformaciones. Resultaba llamativo que después de varias sesiones su rostro siguiera vacío.

$\mathrm{Su}$ evolución no era clara, existía un ir y venir de los miembros del grupo masculino que era observado desde lejos por el femenino, que nunca había querido participar directamente en el robot pese a las invitaciones de los chicos, y al que solo habían contribuido aportando material reciclado.

Como ya sucediera en el trimestre anterior, fue durante una sesión a la que $\mathrm{J}$ no asistió, cuando el grupo puso de manifiesto, (con expresiones como: "J quiere imponerse sobre todo lo que se hace en el grupo", literalmente, "dentro y fuera de la clase"), su cansancio con una situación que consideraban estancada. Se trataron de analizar posibles vías de solución, pero prevalecía la negación del problema en cuanto bidireccional, focalizándose en actitudes de defensa ante J. Paralelamente se produjo un cambio en cuanto a las producciones: colores alegres y cierto aire de manualidades. 
Si bien prácticamente todos se sentían muy satisfechos y contentos con los trabajos realizados, algunos miembros del grupo encontraron el transcurso de la sesión tan "relajado", que llegaron a pensar que quizás no había ocurrido nada relevante durante el trabajo artístico de que hablar o que contar. Hubo que recoger y presentar los diferentes procesos mientras presentaban sus obras al final de la sesión, para encontrar que también se habían producido algunas dinámicas "negativas" como peleas entre hermanos, desacuerdos, etc. que quizá, no deseaban ser vistas.

$\mathrm{P}$, que había tomado un rol marcadamente crítico y proveedor de material del grupo, propuso hacer del robot un proyecto grupal en el que cada uno podría añadir un elemento por turnos. Pero esta idea fue rechazada por $\mathrm{M}$ que, como indiscutible líder del grupo, quizás sintió en la propuesta cierta amenaza para su rol.

En general parecía existir un obstáculo o dificultad de abordaje que apuntaba a una actitud de resistencia al cambio.

\section{Cambios}

En la sesión posterior a la ausencia de $\mathrm{J}$ empezaron a suceder cambios importantes en la operativa grupal. $\mathrm{N}$ se presentó muy disruptivo, molestando a sus compañeros, rompiendo algunas de sus cosas con gestos descuidados y oponiéndose a algunas de las ideas de L sobre el robot. Discutió con él e intentó imponer su opinión sin conseguirlo, por lo que se apartó del grupo-robot y comenzó atrabajar solo.

Mientras tanto J deambulaba por la sala; parecía buscar un hueco a través del cual acercarse sigilosamente al robot, que inundaba con su presencia y tamaño casi toda la mesa de trabajo.

L estaba intentando hacer una abertura a modo de separación de unas piernas para el robot.

M comenzaría como casi siempre ayudando y aportando ideas sobre el trabajo de $\mathrm{H}$, que por aquel entonces seguía enfrascado en un coche, para luego pasar a trabajar sobre el robot, donde iba colocando algunos elementos de "guerra" a modo de vísceras, algo que remitía a cierto carácter "visceral" de la lucha.

$\mathrm{J}$ consiguió finalmente acercarse y participar: primero ayudó a colocar un tirachinas en el pecho y acto seguido, y como L había conseguido abrir "las piernas", volvió a cerrarlas colocando el cartón en su sitio, porque a él no le gustaba el resultado.

Ante esta acción L, quizás paralizado por el miedo a manifestar su rabia e impotencia, sólo acierto a decir: "con lo que me había costado...". M observa y N, al hilo de su actitud provocadora durante la sesión, se ríe.

Durante la presentación de las obras, una parte del grupo expuso su malestar con comportamiento de $\mathrm{N}$ y sus continuas invasiones y agresiones. P puso de manifiesto como le recordaba este comportamiento al de $\mathrm{J}$ cuando éste no respetaba a nadie, y L, a lo mejor animado por la observación de su hermana y quizás de algún modo sintiéndose protegido por ella, señaló el momento cuando $\mathrm{J}$ había vuelto a pegar las 
piernas del robot después del duro trabajo para abrirlas. $\mathrm{N}$ comenzó a defenderse y mencionó que no le gustaba nada "lo de parecerse a J" y menos que se lo dijeran.

Posteriormente se hizo un silencio que J rompió diciendo, mientras miraba a L, que "de momento había pegado las piernas del robot, pero que se podían abrir de nuevo, porque solo había puesto unos celos". M expresó el porqué de su no intervención: no sabía que era peor, pues tenía miedo de que J se enfadara de nuevo.

Las intervenciones parecían haber tenido una resonancia ambiental importante en cada uno de los miembros y podían alentar la toma de responsabilidades individuales, tan necesarias para un cambio. Quizá la expresión de los intensos sentimientos interpersonales, así como los comentarios confrontados y críticos, podrían ejercer alguna presión en algunos de ellos suponiendo la base desde la que pudieran abordar sus problemas.

\section{Finales}

El final se iba acercando, lo que se señalaba al comienzo de cada sesión a modo de recordatorio. Los temas del adiós, propuestas de fiestas para celebrarlo, preguntas de si sería posible continuar el año siguiente se sucedían. Aparecieron temas sobre la despedida de G, que se marcharía para ir al instituto y de cómo ésta temía ese momento. Temas que florecían como el miedo a lo desconocido, repetir curso, la utilidad de la costumbre, servían para seguir dirigiendo sutilmente al grupo hacia los temas de mayor latencia: el cambio y los vínculos afectivos dentro del proceso de individuación.

Durante dos sesiones sucesivas, J parecía haber encontrado un hueco dentro del trabajo del robot armado. Era posible verle intentando gestos de acercamiento: le despegó "las piernas" nuevamente para que L se sintiera mejor y comenzó a pegar algunos artilugios de trabajos personales para hacerlos participar del proyecto, como la cara que había hecho en las primeras sesiones de invierno. Los demás parecían aceptar sus intervenciones sin demasiado reparo.

M seguía participando activamente como cabeza visible del proyecto, y la iniciativa de $\mathrm{J}$ volvió a evidenciar rivalidades. J amenazaba con quitar sus artilugios hasta que finalmente, cuando no encontró la respuesta de apoyo deseada en los demás, los quitó apartándose de nuevo del proyecto.

Parecía existir una cierta satisfacción del resto del grupo, que llevaba a preguntarse si al grupo no le hubiera gustado más que $\mathrm{J}$ hubiera creado su propio robot, para poder así luchar contra él; y si en este interjuego creativo-destructivo, no existía una manifestación retadora y de confrontación grupal que $\mathrm{J}$ no era capaz de aceptar.

Esta vez J no actuó con rabia, ni con desprecio hacia los demás. Se levantó, se llevó sus cosas y se dedicó a colocarlas en una esquina cuidadosamente, como preparándose para irse, para llevárselo todo. Repasó trabajos muy significativos para él y los colocó en un rincón de la clase. Recogió la cara del robot, sus tirachinas, el tanque y su teléfono y los colocó cuidadosamente encima de una especie de cama que había realizado en sesiones de invierno. ¿Era este un gesto de rendición, de abandono? 
Durante la presentación de los trabajos, las chicas, que habían colaborado en distintos collages, obviaron el tema masculino; los chicos no mencionaron lo ocurrido en una suerte de negación colectiva, que sólo se hizo evidente cuando J, durante la última parte de la sesión, muy silencioso, no quiso contar nada acerca de su proceso en la sesión de ese día. Se quedó sentado, tumbado en la mesa, escuchando lo que decían los demás sobre el robot, sin decir nada. Parecía haberse producido una nueva forma de separación del grupo. El grupo parecía esperar en silencio la explosión de rabia a la que estaba acostumbrado. P, que parecía vivir este silencio con angustia, se levantó, y dijo estar cansada, que quería irse a casa.

\section{Despedida}

La última sesión quedó para hacer un recorrido por las obras. Se dejó un espacio donde se pudieran ver, y reflexionar sobre ellas y sus procesos: qué diálogos sugerían, como habían cambiado en el transcurso del tiempo y del taller.

Los trabajos grupales habían de ser compartidos, divididos, o rifados y además se presentaban como testigos de las alianzas y de los desencuentros.

Se evidenció que era la última sesión en muchas manifestaciones: piernas que se movían, agitación de las manos, ruido con las sillas, risas descontroladas, comentarios de pena y tristeza por el final, etc.. El grupo tardó en colocarse haciéndose eco de una resistencia ante la despedida.

Cada cual fue invitado a mirar en sus obras, a sentirlas, a revisarlas, a discriminar los trabajos realizados y valorar si era necesario algún cambio, si algo quería ser descartado o compartido, para luego expresarlo en el grupo. Empezaron hablando de lo que a cada uno le había gustado más hacer mientras separaban lo que no les gustaba, a modo de selección.

El robot parecía invadir con su presencia la clase. Fue colocado en el círculo, como si se tratara de un miembro más, como espectador y como testigo de un proceso de alianzas y contraalianzas de los trabajos grupales. Surgieron los primeros comentarios acerca de las armas de los chicos, también de la agresividad, de la que no quería participar el grupo femenino, que había ido conformando sus trabajos alrededor de manifestaciones mas identificatorias e intersubjetivas.

Se evidenciaron las divisiones: femenino y masculino, pequeños y mayores; y otros temas como las ausencias y las incorporaciones de miembros al grupo y lo que esto había significado durante nuestra trayectoria.

Se pusieron de manifiesto los papeles que cada uno había tomado en estos procesos, como cuando hicieron los teléfonos móviles, mostrando así la necesidad de mantenerse comunicados, y de incorporar a esta red comunicativa a los nuevos miembros como $\tilde{\mathrm{N}}$.

El gran robot confrontó al grupo con todos esos aspectos de exclusión vividos fuertemente por algunos de sus miembros y con los sentimientos que esto generaba, dentro y fuera; con la forma en que en este interjuego se operaban mecanismos defensivos de agresión y proyección; con los aspectos que más molestaban e impedían una vinculación sana y menos angustiosa. 
Los chicos fueron capaces de participar de estas observaciones reconociendo con sus propias palabras como se producían los hechos y los juegos de poder. J apenas se defendía y llegó a señalar como en cierto modo él había querido que Ñ sintiera lo mismo que él dentro del grupo, porque a él le habían impedido participar en el robot. Otros señalaron como había sido él quien se separó de los demás "siempre enfadado", queriendo imponer sus opiniones. Las chicas aprovecharon para señalar su cansancio ante tantos acontecimientos beligerantes al no querer participar del robot directamente.

Un sin fin de aspectos de tristeza emergieron durante la despedida, en forma de recapitulaciones sucesivas de hechos acontecidos, como la despedida de $\mathrm{K}$, el malestar de $\tilde{\mathrm{N}}$ y J identificados como agentes excluidos, etc. La reelaboración de estos aspectos relacionados con la realidad grupal, daba cuenta de como el grupo, en cierto modo, podía sentirse más seguro y tranquilo en este espacio que habían hecho suyo y donde las angustias eran más llevaderas, permitiendo la posibilidad de hablar de lo que les molestaba, teniéndose en cuenta mutuamente y favoreciendo el vínculo.(Bowlby, 1997)

El robot grande parecía un gran catalizador con su imponente presencia porque parecía haberse convertido en un eje vital para el grupo, testigo de su historia, con la fuerza de los elementos que le conformaban y de los ausentes y desprendidos.

Discutían dónde llevarían sus robots y el armamento compartido. Hablaron de llevarlo a una casita de madera que se habían construido en un árbol del pueblo. “¿Entre todos?”, pregunté. "Bueno, más o menos” me respondieron.

\section{A MODO DE CONCLUSIÓN}

Haciendo un juego de analogías con el título de este artículo, a groso modo casi parece haber una evolución natural, coincidente con las estaciones del año, en la forma en que la dinámica grupal atravesó distintos momentos en su desarrollo. (Pichón Riviére, 1988)

- Otoño. Momento pretarea o de desconcierto inicial.

- Invierno. Momento de tarea, con emergentes mas definidos y donde se afrontan tareas nuevas en coherencia grupal y aparecen y se empiezan a elaborar las ansiedades básicas.

- Primavera: Momento proyecto y de resolución de conflictos, coincidente con el final, activando la elaboración de los límites de los trabajos individual y grupal realizados, el nivel de insight, de cambio y de aprendizaje alcanzado.

La aparición del robot como elemento emergente fue el detonante de nuevas dinámicas a través de las cuales pudieron hacerse evidentes otras, más encapsuladas, que afectaban al funcionamiento del grupo tanto como a cada uno de sus miembros. El trabajo realizado fue capaz de poner en marcha un movimiento hacia posiciones más realistas, más conscientes y por lo tanto más flexibles, gracias a lo cual fue posible cierta apertura hacia la aceptación del otro y de sus diferencias. 


\section{REFERENCIAS BIBLIOGRÁFICAS}

BION, W.R. (1985).Experiencia en grupos. Barcelona, España: Ediciones Paidós.

CASE, C. y DALLEY, T (1992) The handbook of art therapy .Londres: Rautledge

FRANKS, M. y WHITAKER, R. (2007) The image, mentalitation and group art psychotherapy. INSCAPE Vol.12 (1): 3-16.

FOULKS, (1981) Psicoterapia Grupo-Analítica: Método y principios. Barcelona: Gedisa.

LEIBMANN, M. F. (1986) Art Therapy for Groups: A Handbook for Themes, Games and Exercise. London: Croom Helm

LÓPEZ FERNANDEZ CAO, M. y MARTINEZ DÍEZ, N. (2006) Arteterapia .Conocimiento interior a través de la expresión artística. Madrid: Tutor

PICHÓN RIVIÈRE, E. (1984) Teoría del vinculo. Buenos Aires: Nueva Visión. $21^{\mathrm{a}}$ edición.

PICHON RIVIÈRE, E.(1988) El proceso grupal. Del psicoanálisis a la psicología social. Buenos Aires: Nueva Visión.

SÁENZ BERMEJO, F. (2008) Winnicott, un buen compañero de viaje Madrid: Psimática

SHAVERIEN, J. (1999). The Revealing Image: Analytical Art Psychotherapy in Theory and Practice (1 ed.). Philadelphia: Jessica Kingsley Publishers.

\section{NOTA DE AUTOR SOBRE LA BIBLIOGRAFÍA:}

Las referencias bibliográficas hacen alusión al material bibliográfico básico para entender y profundizar en una primera toma de contacto con el tema que se expone en este artículo, referente a las sesiones de Arteterapia grupal en el contexto educativo. El resto de autores referenciados que aparecen en el texto en ocasiones y que no aparecen en la bibliografía básica, corresponden a menciones especiales que aportan citas o elementos puntuales, que por un lado son muy útiles para ilustrar el pasaje referido, y por otro pueden ser fácilmente encontrados en bibliografías mas amplias sobre temas psicoanalíticos y de intervención grupal más allá del Arteterapia. 